\title{
Nocturnal observations of the semidiurnal tide at a midlatitude site
}

\author{
R. J. Niciejewski and T. L. Killeen \\ Space Physics Research Laboratory, University of Michigan, Ann Arbor
}

\begin{abstract}
Fabry-Pérot interferometer observations of the mesospheric hydroxyl emission and the lower thermospheric O I ( $5577 \AA)$ emission have been conducted from an airglow observatory at a dark field site in southeastern Michigan for the past several years. The primary functions of the observatory are to provide a database for correlative observations with the UARS satellite and to provide a synoptic measurement program for the coupling energetics and dynamics of atmospheric regions effort. An intensive operational effort between May 1993 and July 1994 has resulted in a substantial data set from which neutral winds have been determined from the bifilter acquisition sequence. A "best fit" analysis in the least squares sense of the simultaneous measurements of the neutral winds to a 12-hour periodicity has provided amplitude and phase parameters for the semidiurnal tide as well as a measure of the mean wind. The measured tidal amplitude is greater at the higher altitude, though the seasonal behavior at both altitudes is similar with greater amplitudes during August/September and April/May. Both meridional and zonal wind components are consistent with a semidiurnal tidal description during the entire observational sequence except for the May to July 1993 period. The mean winds show annual variation in the meridional flow, being equatorward from May to October and poleward during the winter. The zonal flow is primarily eastward during the entire observational window with higher speed flows during May/June at the higher altitude and June/July at the lower altitude. A comparison with a semidiurnal tidal model indicates that the measured tidal amplitudes are a factor of 2 times greater, while the phases show similar equinoctial transitions.
\end{abstract}

\section{Introduction}

The dynamics of the terrestrial mesosphere play an important role in coupling the higher thermospheric regions with the lower portions of the Earth's atmosphere. Atmospheric tides provide a means for the propagation of energy from "source" regions at low altitudes to "breaking" regions at high altitudes where the energy is dissipated. At midlatitudes, the solar semidiurnal tide may easily be observed in daily time series of various geophysical parameters characteristic of the mesosphere and lower thermosphere. At these latitudes, the forcing mechanism for the semidiurnal tide is thermal in nature being excited by the absorption of solar ultraviolet radiation by water vapor in the troposphere and the absorption of solar ultraviolet and extreme ultraviolet by ozone in the stratosphere and lower mesosphere [see Chapman and Lindzen, 1970]. The tidal energy propagates upward forcing an altitudinally dependent semidiurnal variation in local temperature, density, and horizontal winds until dissipation of the energy occurs somewhere in the thermosphere.

Time series of geophysical parameters in the mesosphere and lower thermosphere are exceptionally difficult to observe. In situ observations are fleeting, accomplished only by sounding rockets. Satellites are beginning to provide data sets, though concerns relating to aliasing and spatio-temporal ambiguities may exist. Ground-based experimental probing of the mesosphere and lower thermosphere has usually been restricted

Copyright 1995 by the American Geophysical Union.

Paper number 95JD02729.

0148-0227/95/95JD-02729\$05.00 to remote sounding via MF radars or partial reflection systems [Manson and Meek, 1984], and meteor radars (mesosphere stratosphere troposhere or MST radars operating as meteor radars) [Clark, 1983], and more recently, light detection and ranging (LIDAR) [Gardner et al., 1989], and optical spectroscopic techniques [Rees et al., 1990]. Each of these methods has been used to study the effects of gravity wave breaking and tidal influences in the mesosphere. Until recently, optical observations of the hydroxyl airglow have primarily yielded only temperature and intensity measurements [e.g., Sivjee et al., 1987]. However, exploratory work by Hernandez and Smith [1984] and more recently by Rees et al. [1990] have shown that it is possible to measure mesospheric winds by observing the Doppler shift of emissions from the hydroxyl radical, the technique being well demonstrated at the South Pole Station [Hernandez et al., 1993, and references therein]. Ground-based optical observations of Doppler shifts of the O I ( $5577 \AA$ ) emission are more routine though potentially contaminated by auroral precipitation [Cogger et al., 1985] and upper thermospheric airglow emission [Wiens et al., 1988]. Unfortunately, for validation purposes, comparisons between optical and radio techniques are exceedingly difficult to perform since the two observation techniques are usually mutually exclusive in time [Lloyd et al., 1990]. Finally, observations by incoherent scatter radar have provided some insight into the behavior of the midlatitude semidiurnal tide by extracting neutral wind information from $E$ and $F$ region plasma drift measurements [Wand, 1983].

Theoretical studies of the tidal structures in the mesosphere and lower thermosphere have progressed significantly since the work of Chapman and Lindzen [1970]. An important, sem- 
inal contribution is that of Forbes and Vial [1989]. Here a theoretical simulation of the solar semidiurnal tide was performed on a global scale for altitudes between 80 and $150 \mathrm{~km}$ on a monthly mean basis. Unfortunately, the simulation fared poorly for altitudes above $105 \mathrm{~km}$ and is not considered valid due to certain parameterizations of molecular diffusion of heat and momentum. In order to improve the simulation for lower thermospheric altitudes, tidal data acquired by the worldwide net of radar observatories were assimilated into a global, selfconsistent empirical description of the semidiurnal tide [Forbes et al., 1994]. As these theoretical tidal descriptions mature, it is likely that the thermospheric general circulation models (TGCM) [e.g., Roble et al., 1988] which previously were valid for only higher thermospheric altitudes may be extended downward in altitude to include the mesosphere.

We report in this paper initial, simultaneous observations of mesospheric and lower thermospheric winds based on a new detection technique, a Fabry-Pérot interferometer utilizing a "bare" CCD as the detector. The experiment is one of several that are supported by the coupling energetics and dynamics of atmospheric regions (CEDAR) program devoted to supplying experimental observations of the coupling, energetics, and dynamics between the various delineated regions of the terrestrial atmosphere. To our knowledge, these are the first scientific results of tidal dynamics using this bifilter method. The continued use of this simple optical technique shall provide desperately needed validation measurements to unravel the cause of discrepancies that are present with certain radar wind measurements [Hines et al., 1993; Burrage et al., 1995].

\section{Experiment}

The Space Physics Research Laboratory of the University of Michigan has long been involved in performing ground-based observations of diffuse weak airglow emissions. A network of airglow observatories was established in the early 1980s to monitor the thermospheric O I $(6300 \AA)$ emission utilizing the
Fabry-Pérot interferometer technique [Meriwether et al., 1983]. The experiment permits the detailed examination of a spectral emission "line" from which temperature is extracted from the Doppler broadening of the feature, and line of sight bulk gas motion is measured by the Doppler shift in the center wavelength of the feature. Geophysical determinations are susceptible to ambiguities resulting from instrumental artifacts convolved into the observations, but with careful alignment and calibration as well as attention to environmental changes in the observatory, excellent studies may be performed. Such has been the case for observations of the O I (6300 $\AA$ ) feature [e.g., Meriwether and Shih, 1987; Meriwether et al., 1988] and with this experience, a program to observe the hydroxyl airglow was initiated in 1989. The hydroxyl observations are inherently more difficult, but the problems have been surmounted [Niciejewski et al., 1994].

An airglow observatory, shown in Figure 1, was established in 1989 at a dark field site 15 miles northwest of Ann Arbor, Michigan, in the Stinchfield Woods at a location known as Peach Mountain. The instrument complement includes the Fabry-Pérot interferometer, a Michelson interferometer [Niciejewski and Killeen, 1995], and an all-sky imager [ $W u$ and Killeen, 1994]. The program is designed to provide longterm measurements of the dynamics in the mesosphere and lower thermosphere at a midlatitude site. The front end of the Fabry-Pérot interferometer is similar to those employed in Greenland described by Meriwether et al. [1983], but the back end utilizes a bare charge-coupled device and a microprocessor controlled data acquisition system as shown in Figure 2. Operational parameters of the Fabry-Pérot interferometer are listed in Table 1.

The key component which permits detailed observation of a hydroxyl emission feature is the bare charge-coupled device (CCD). The hydroxyl nightglow is most intense in the near infrared, though pioneering observations in the far-red visible region were performed by Hernandez and Smith [1984]. With

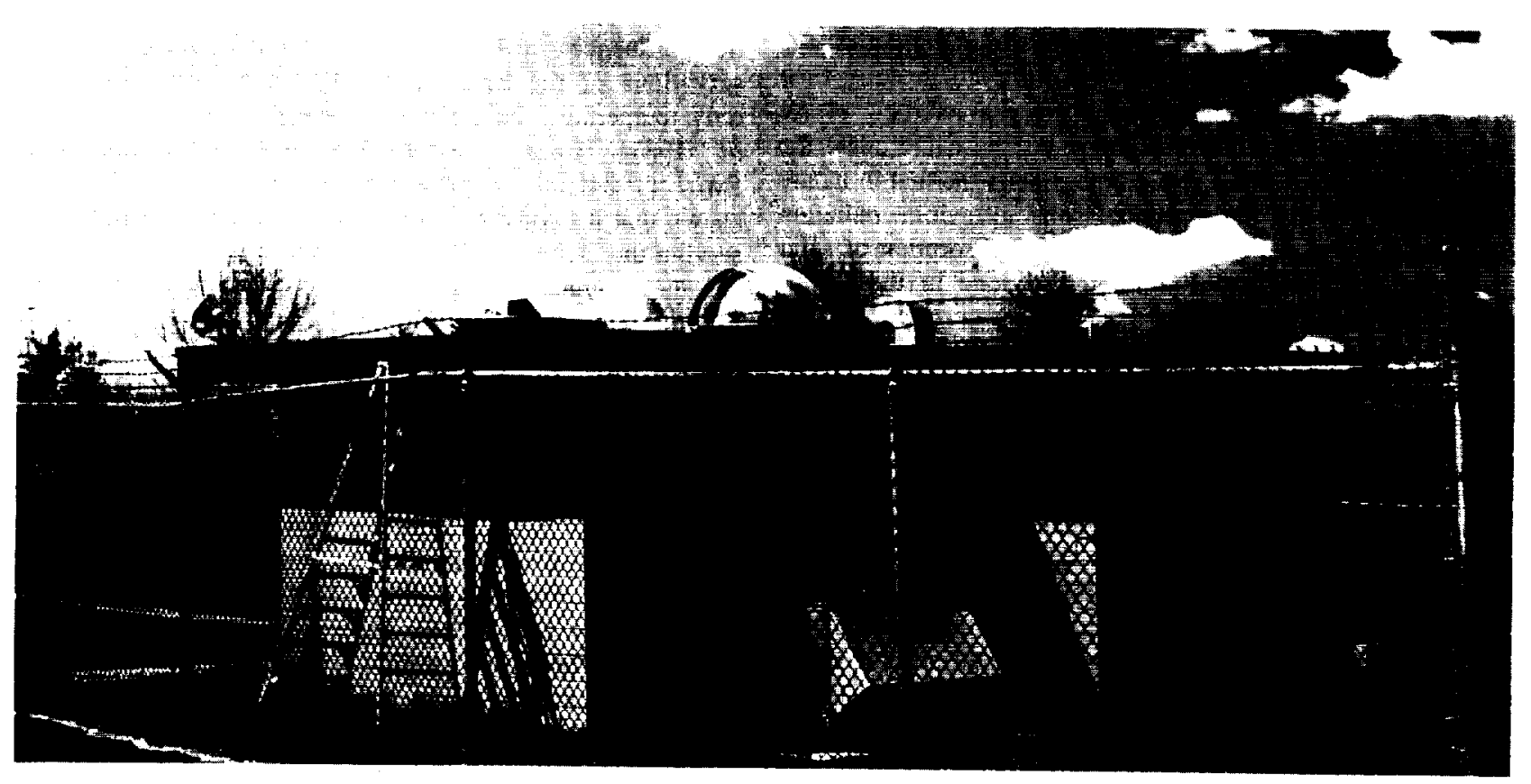

Figure 1. Photograph of the airglow observatory at the Peach Mountain field site. All instruments are located in a dark room, each occupying a spot beneath a Plexiglas dome. The building is maintained at a constant temperature by an environmental control system. 


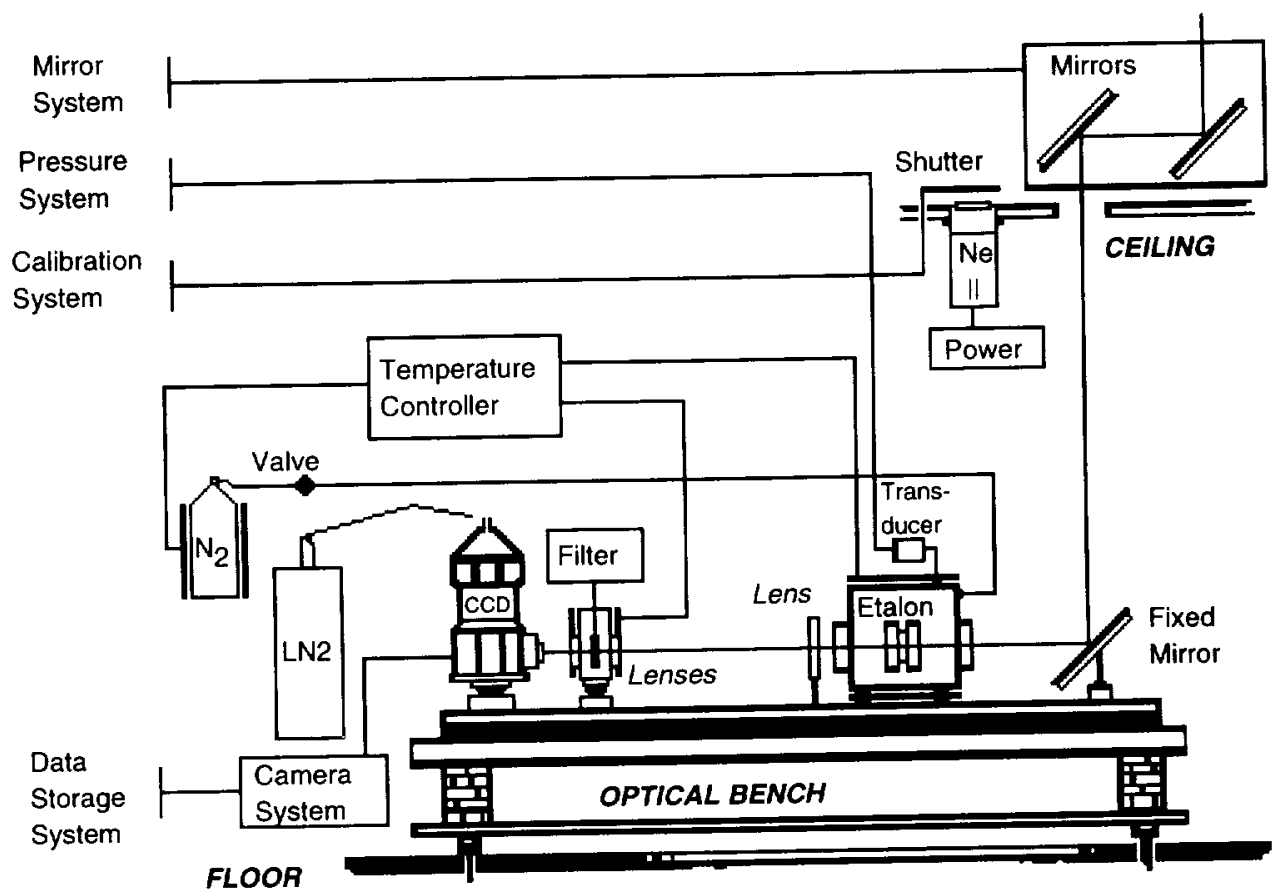

Figure 2. Schematic diagram of the Fabry-Pérot interferometer experiment at Peach Mountain. Key elements (pressure control piston, etalon chamber, and interference filter wheel) of the design are kept at constant temperature by an active temperature control system. The sky-scanning mirror system permits pointing to any spot in the sky. Lenses are achromatic.

the development of the low-noise, scientific grade CCD, reasonable sensitivity could be obtained in the near infrared providing a better mechanism for observing the hydroxyl line feature. Examples of fringe profiles for a hydroxyl rotational line and the O I ( $5577 \AA)$ feature observed at Peach Mountain are shown by Niciejewski et al. [1994].

There were several specific difficulties encountered in mating a bare CCD detector with a Fabry-Pérot interferometer and deploying for mesospheric wind observations. It was decided at the start that to improve the accuracy of a geophysical parameter measurement, the imaging of several fringes would be

Table 1a. Optics Facts for the Fabry-Pérot Interferometer at Peach Mountain Airglow Observatory

\begin{tabular}{|c|c|c|}
\hline \multicolumn{2}{|c|}{ Feature } & Description \\
\hline \multicolumn{2}{|c|}{$\begin{array}{l}\text { Etalon plates manufactured by ZYGO with } \\
\text { reflectivity at } 5577 \AA \\
\text { reflectivity at } 8920 \AA \\
\text { Clear aperture } \\
\text { Spacer gap ( } 3 \text { solid zerodur units) } \\
\text { Typical working finesse for innermost channel }\end{array}$} & $\begin{array}{l}80 \% \\
65 \% \\
10 \mathrm{~cm} \\
2.0 \mathrm{~cm} \\
14\end{array}$ \\
\hline Lens* & Diameter, cm & Focal Length, $\mathrm{cm}$ \\
\hline $\begin{array}{l}\text { Objective } \\
\text { Collimating } \\
\text { Condensing }\end{array}$ & $\begin{array}{r}15 \\
5 \\
5\end{array}$ & $\begin{array}{r}150 \\
30 \\
8\end{array}$ \\
\hline
\end{tabular}

*The lens combination given above implies nearly four complete free spectral ranges at $\lambda 6328 \AA$ imaged onto the detector. The free spectral range is $0.08 \AA$ at $\lambda 5577 \AA$ and $0.20 \AA$ at $\lambda 8920 \AA$. required. For example, a representative mesospheric wind measurement is 10 to $20 \mathrm{~m} / \mathrm{s}$, while the older, traditional upper thermospheric wind measurements were of the order of 100 to $200 \mathrm{~m} / \mathrm{s}$ with an uncertainty of $\pm 10 \mathrm{~m} / \mathrm{s}$. To decrease the uncertainty in the wind measurement, very accurate determinations of the center position of the fringe profiles were required. Inherent noise in the observations were produced by cosmic ray bombardment on the silicon die and detector noise limitations. The removal of cosmic ray noise was straightforward since only a few pixels were hit during any integration and these were easily identified. Detector noise was kept to a minimum by coadding adjacent pixels on the CCD into larger "superpixels" prior to output through a preamplifier. The thermal contribution to the noise on a pixel was basically eliminated by cryogenically cooling the CCD with liquid nitrogen. Electronic bias in the detection and amplification chain was characterized prior to and subsequent to each sky fringe profile image. Consequently, the representative uncertainty in a 5 -min mesospheric wind measurement was about \pm 5 $\mathrm{m} / \mathrm{s}$ or less.

Table 1b. Filter Wheel Facts for the Fabry-Pérot Interferometer at Peach Mountain Airglow Observatory

\begin{tabular}{cccc}
\hline & $\begin{array}{c}\text { Center } \\
\text { Wavelength, } \AA\end{array}$ & $\begin{array}{l}\text { Band } \\
\text { Pass, } \AA\end{array}$ & Transmission, \% \\
\hline 1 & 8920 & 8 & 70 \\
2 & 5577 & 8 & 60 \\
3 & open & 5 & 30 \\
4 & 6305 & & \\
5 & open & & \\
6 & open & & \\
\hline
\end{tabular}


Table 1c. Detector Facts for the Fabry-Pérot Interferometer at the Peach Mountain Airglow Observatory

\begin{tabular}{lr}
\hline \multicolumn{1}{c}{ Feature } & \multicolumn{1}{c}{ Description } \\
\hline $\begin{array}{l}\text { Thomson TH7882 CDA with } \\
384 \times 576 \text { pixels }\end{array}$ & pixel size is $23 \times 23 \mu \mathrm{m}$ \\
Readout noise & $11.5 \mathrm{e}-\mathrm{RMS}$ with bias included \\
Dark noise & $4.1 \mathrm{e} /$ min at $-120^{\circ} \mathrm{C}$ \\
\hline
\end{tabular}

The Fabry-Pérot interferometer was easily deployed as a remotely controlled experiment acquiring sky fringes every day between dusk and dawn. The integrity of the experiment was monitored by telephone line using a modem connection. Cloud cover information was obtained from the Detroit Metro Airport meteorological service at 1 -hour intervals and used to remove poor quality data. The primary handicap in the 15 -month intensive observational campaign was the cryogen requirement. The 160-L supply dewar would keep the detector cold between 10 and 18 days depending on the insulation characteristics of the dewar and the leakage of evaporated gas to the ambient environment. Delays in refilling the supply dewar accounted for up to 1 week of down time per month.

The campaign period lasted from early May 1993 to late July 1994 providing one full annual cycle with two summer seasons. The observational cycle for the Fabry-Pérot interferometer was composed of a five position measurement sequence, remaining at a position for each filter measurement. The field of view of the system was $0.63^{\circ}$. To measure the horizontal wind, a set of four orthogonal pointing directions were chosen corresponding to the cardinal compass directions. The elevation angle was 30 degrees for these measurements. Zenithal measurements were also acquired, though the integration period for these were increased by $50 \%$ to account for the decreased columnar emission rate. Initially, the interference filters employed were old and had low transmissions within their band passes. Consequently, the integration periods were of the order of 10 min per measurement. The $8920-\AA$ filter was replaced in November 1993 and the $5577-\AA$ in March 1994. This permitted the reduction of a single integration to $3 \mathrm{~min}$ per measurement. These faster integration rates allowed more detailed characterization of the wind fields associated with gravity wave features visible in the hydroxyl airglow and will be the subject of a future contribution. In the present study the longer integrations were acceptable for characterizing the semidiurnal tide. Instrumental calibrations were routinely performed at roughly 2 -week intervals and led to a complete characterization of the long-term behavior of the instrument itself.

\section{Results}

\section{Data}

Each nightly series of images was archived prior to analysis. The raw images were reduced into wavelength space using the technique described by Mulligan [1986]. This provided fringe profiles from annular or ring-sum bins. Geophysical parameters were extracted from the multiple fringe profiles using a technique based on that of Killeen and Hays [1984]. The instrumental calibrations were performed with a frequency stabilized $\mathrm{HeNe}$ laser and then the instrumental response functions were transferred to each observational wavelength. Uncertainties in the reflectivity of the etalon plates made neutral temperature extraction quite difficult but did not compromise the neutral wind measurements. No attempt was made to calibrate the absolute emission rate of hydroxyl or the O I $(5577 \AA)$ airglow, since their absolute values are not germane to the present study. Regardless, the absolute values could be evaluated by transferring intensity calibrations from collocated adjacent instruments.

Figure 3 displays an example of a reduced data set for day number 111 of 1994 (evening of April 21, morning of April 22). Here each panel displays a different geophysical determination including horizontal and vertical wind components, neutral temperature, emission rate, and background intensity, and a chi-square "goodness of fit" parameter. For the wind components, meridional is positive northward, zonal is positive eastward, and vertical is positive upward. Midnight occurs at $0500 \mathrm{UT}$. Figure 3 a refers to the higher altitude O I $(5577 \AA)$ measurement, while Figure $3 \mathrm{~b}$ corresponds to the lower hydroxyl measurement. In this particular example, there is about a 3-hour difference between the meridional and zonal wind components with the meridional leading, as well as an altitudinal phase shift corresponding to downward phase propagation and a vertical wavelength of $\sim 60 \mathrm{~km}$. The intensity values are normalized to unit time with the effect of highlighting the lower intensity zenithal measurements.

\section{Semidiurnal Fit}

The nightly data sets were entered into a database along with cloud cover records. Much of this data may be accessed via the National Center for Atmospheric Research (NCAR)-CEDAR database system. Cloud cover numbers, in this case, refer to the number of tenths of the sky that are obscured by any cloud. In the fitting procedure described below, wind data corresponding to cloud cover greater than 4 have been discarded. Initially, the wind data were examined on a seasonal basis, but it quickly became apparent that interesting features were being missed entirely by the coarse binning. The quantity of data acquired during the intensive campaign effort made it possible to subdivide data sets into monthly intervals, matching the presentation frequency used by the radar community.

The monthly wind data were examined for evidence of periodic behavior. Least squares fitting to functions representing the diurnal frequency and its harmonics was attempted, with the result that the best fit, in the least squares sense, occurred when only the semidiurnal period was used. For each month, the wind amplitude data, $C(t)$, for each horizontal component were fitled to the linear function

Figure 3. Standard geophysical data display for Peach Mountain Fabry-Pérot interferometer data. Meridional wind is shown with north positive, zonal shown with east positive, and vertical shown with upward positive. The signal and background intensity values are shown per unit time on a relative scale. The wind and temperature points are shown with vertical error bars, being roughly $\pm 3 \mathrm{~m} / \mathrm{s}$ for the wind data and $\pm 6 \mathrm{~K}$ for temperature. The chi-square parameter is relatively stable throughout the night, rising during the twilight hours corresponding to the difficulty in fitting the background intensity. (a) $\mathrm{O} I(5577 \AA$ ) data. (b) Hydroxyl data. 

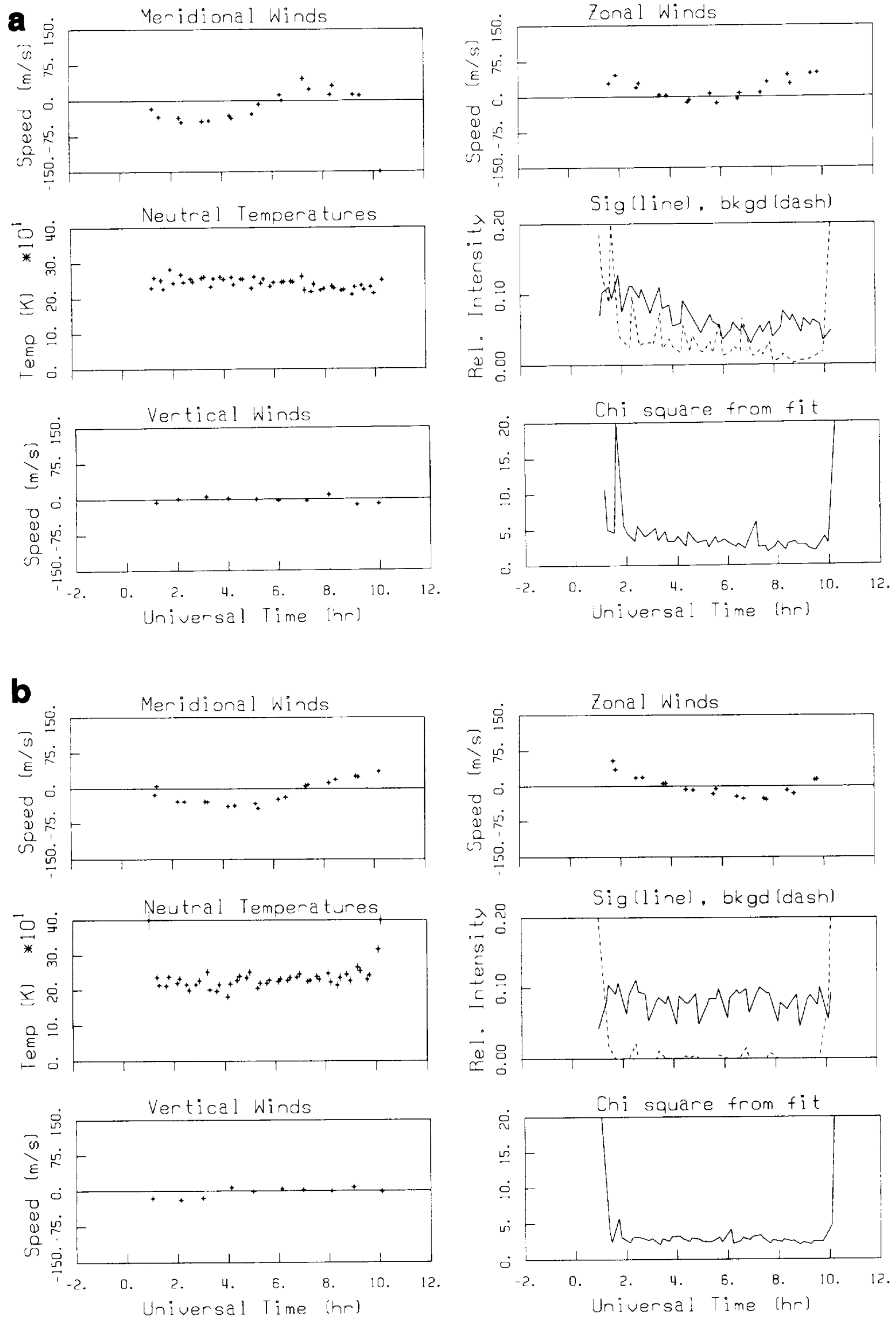


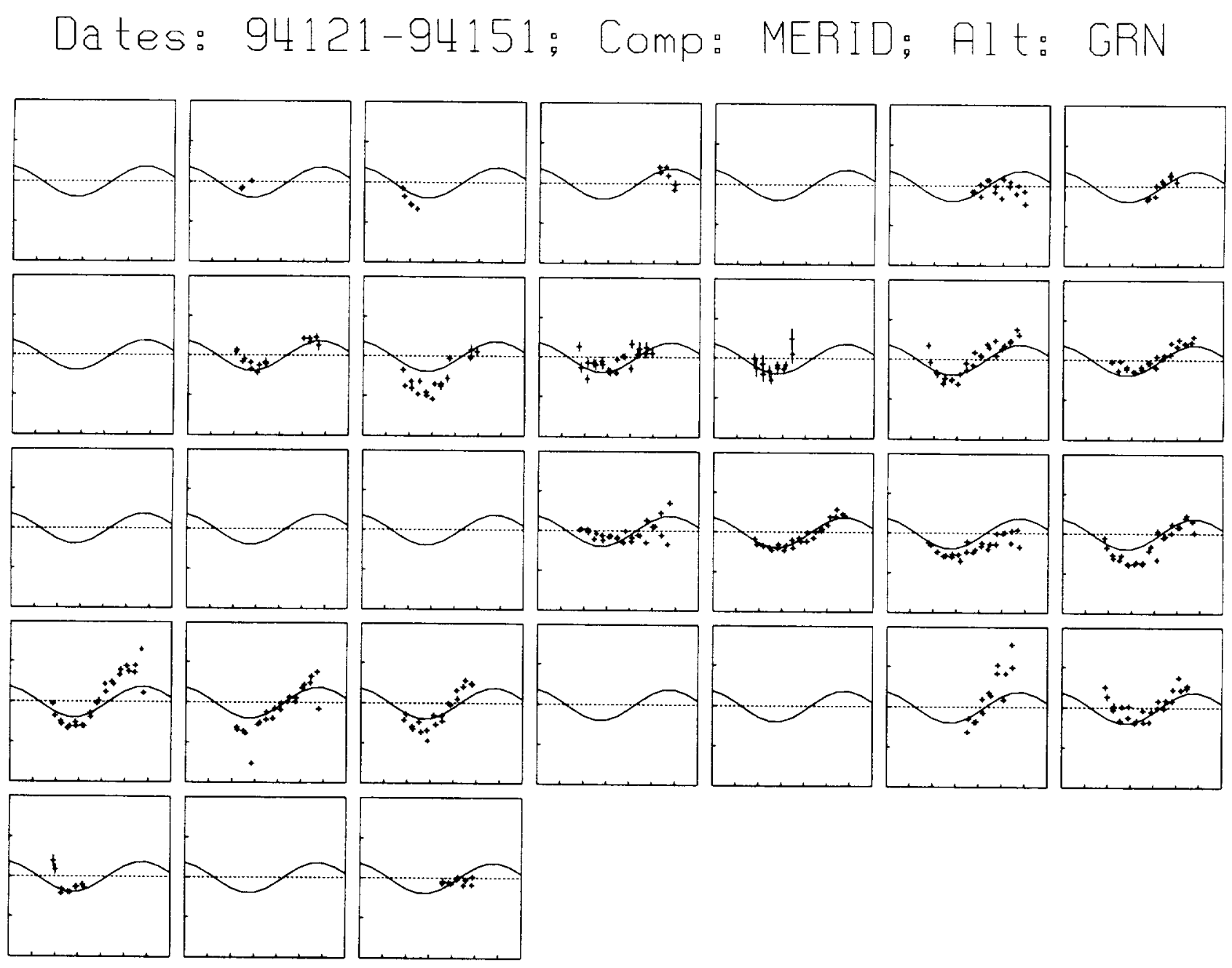

Figure 4. Comparison of the meridional wind data for May 1994 (day number 121 to 151) acquired with the green filter to a least squares fit with a 12-hour periodicity. The axes are time at 2 -hour intervals and wind amplitudes at $75 \mathrm{~m} / \mathrm{s}$ intervals. Each element in the array corresponds to 1 night during the month. Blank windows and abbreviated data sets indicate periods when the measurements were contaminated by clouds.

$$
C(t)=a_{0}+d \sin \frac{2 \pi}{12} t+e \cos \frac{2 \pi}{12} t
$$

for both the O I (5577 $\AA$ ) and the hydroxyl measurements. The amplitude and phase of the semidiurnal tide were extracted from the $d$ and $e$ amplitudes. Time, $t$, was enumerated from the start of each month. The mean wind amplitude, $a_{0}$, was chosen as north and east positive. Figure 4 provides an example of the fit for one of the components for the campaign period, here the May 1994 meridional wind data for the O I (5577 $\AA)$ emission. There is some day-to-day variability, though the fitting function performs a reasonable job in characterizing a "mean" day for the period. In this particular case, 385 points were fit giving a prevailing meridional wind of $-0.7 \pm 0.2 \mathrm{~m} / \mathrm{s}$, and a semidiurnal component of amplitude $28.9 \pm 0.3 \mathrm{~m} / \mathrm{s}$ and phase $-2.46 \pm .01$ hour UT, the uncertainty values being representative of the entire campaign period. No reduction in the residuals was made when, for example, a fit including a diurnal variation was introduced. The blank windows and the abbreviated data sets indicate periods contaminated by cloud cover.

Figure 5 provides a concise method of viewing the semidiurnal parameters for the entire 15 -month data set. The contour plot style has long been employed by both the radar and the theoretical communities for displaying height profiles of semidiurnal and prevailing winds through the mesosphere and lower thermosphere. Though its use may be inappropriate in the present case, consistency and ease of comparison with the published literature provide it great utility. The generally accepted altitudes for maximum emission from hydroxyl and $O$ I $(5577 \AA)$ were chosen as altitudinal boundaries with intermediate points connected using bilinear interpolation. Here solid amplitude contours are shown every $10 \mathrm{~m} / \mathrm{s}$ and solid phase contours every 2 hours. The phase corresponds to the local solar time of maximum northward and eastward wind. The semidiurnal tidal amplitudes are greatest generally during the equinox months surpassing $30 \mathrm{~m} / \mathrm{s}$ during the autumnal equinox and least during the winter months dropping below $10 \mathrm{~m} / \mathrm{s}$. The phases undergo a rapid transition following the autumnal equinox, where the meridional phase rises from 3 to 7 hours and the zonal from 6 to 10 hours in the span of about 45 days. The phase transition in the vernal equinox is less striking though the amplitudes rise from 10 to $20 \mathrm{~m} / \mathrm{s}$. Uncertainties in the least squares values were typically less than $\pm 1 \mathrm{~m} / \mathrm{s}$ for the amplitudes and \pm 0.1 hour for the phases with typically 100 
Semi-diurnal tide, Peach Mountain, MI
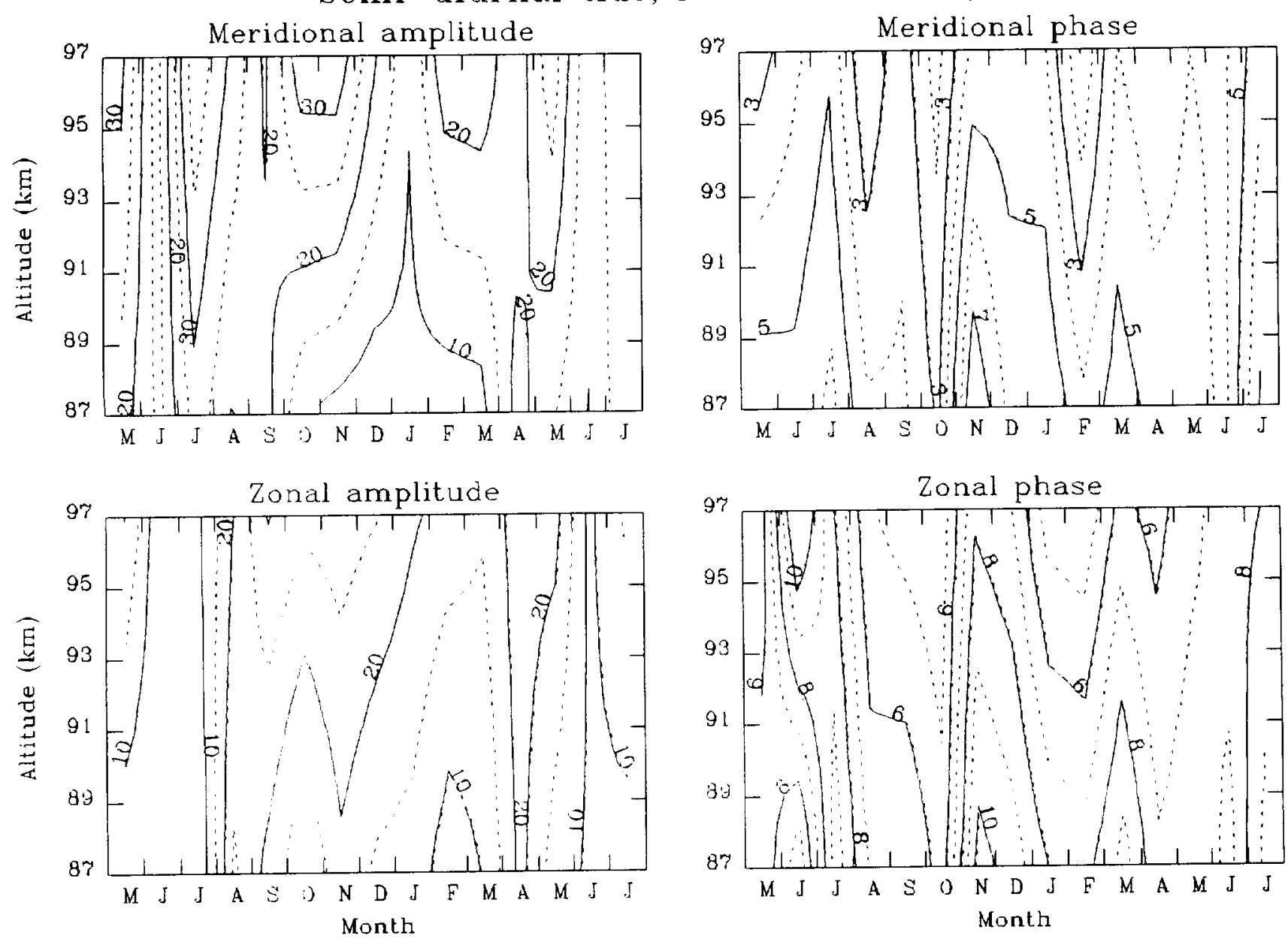

Figure 5. Amplitudes and phases of the semidiurnal tide above Peach Mountain between the months of May $1993(\mathrm{M})$ and July 1994 (J) for both the meridional and the zonal components. The altitudes corresponding to the maximum emission rates for hydroxyl and O I $(5577 \AA)$ were chosen as 87 and $97 \mathrm{~km}$, respectively. Solid contours are spaced at $10 \mathrm{~m} / \mathrm{s}$ for the amplitudes and 2 hours for the phases, with phase corresponding to the local solar time of maximum northward and eastward winds.

points per month using the old filters rising to 300 points per month with the newer interference filters.

The meridional and zonal mean winds are displayed at the top of Figure 6 using the same contouring format. The meridional mean wind is equatorward from May to October 1993 and then again after March 1994 reaching its greatest magnitude in April. During the winter months, the meridional mean flow is poleward. The zonal flow is nearly always eastward surpassing $20 \mathrm{~m} / \mathrm{s}$ during the summer periods. Weakest eastward flows occur during the equinoctial seasons.

It is interesting to check the coherence of the semidiurnal tides along the two orthogonal horizontal components. The bottom of Figure 6 displays the amplitude and phase differences between the measured zonal and meridional components. The first contour for the differences occurs at $5 \mathrm{~m} / \mathrm{s}$ for amplitude and 0.5 hour for phase. Inherent in the phase difference is an assumed 3-hour difference. The meridional and zonal semidiurnal tidal amplitudes are usually within $5 \mathrm{~m} / \mathrm{s}$ of each other except for an interesting period during summer 1993. The two phases are nearly always within 0.5 hour of being in quadrature except also during summer 1993. The only other major departure is during the winter solstice period.

\section{Model}

The simulations of the semidiurnal tide by Forbes and Vial [1989] for $42^{\circ} \mathrm{N}$ latitude are shown in similar contour format in Figure 7. Only the output between 87 and $97 \mathrm{~km}$ is shown, with the meridional direction chosen as north positive (in contrast to the original publication). The close similarity between the meridional and the zonal output is inherent to the model. Simple bilinear interpolation was used in displaying these contours making them appear rougher than in the original publication, though there is nothing intrinsically different between the presentations. The semidiurnal amplitude surpasses $15 \mathrm{~m} / \mathrm{s}$ at the higher altitude during the winter period and is less than $5 \mathrm{~m} / \mathrm{s}$ at the lower boundary. The phase undergoes a rapid transition during both equinoxes.

\section{Discussion and Conclusions}

\section{Altitude of Emission}

The ground-based Fabry-Pérot interferometer observations of the nightglow emissions are passive in nature and do not specifically provide altitudinal information. Nevertheless, 

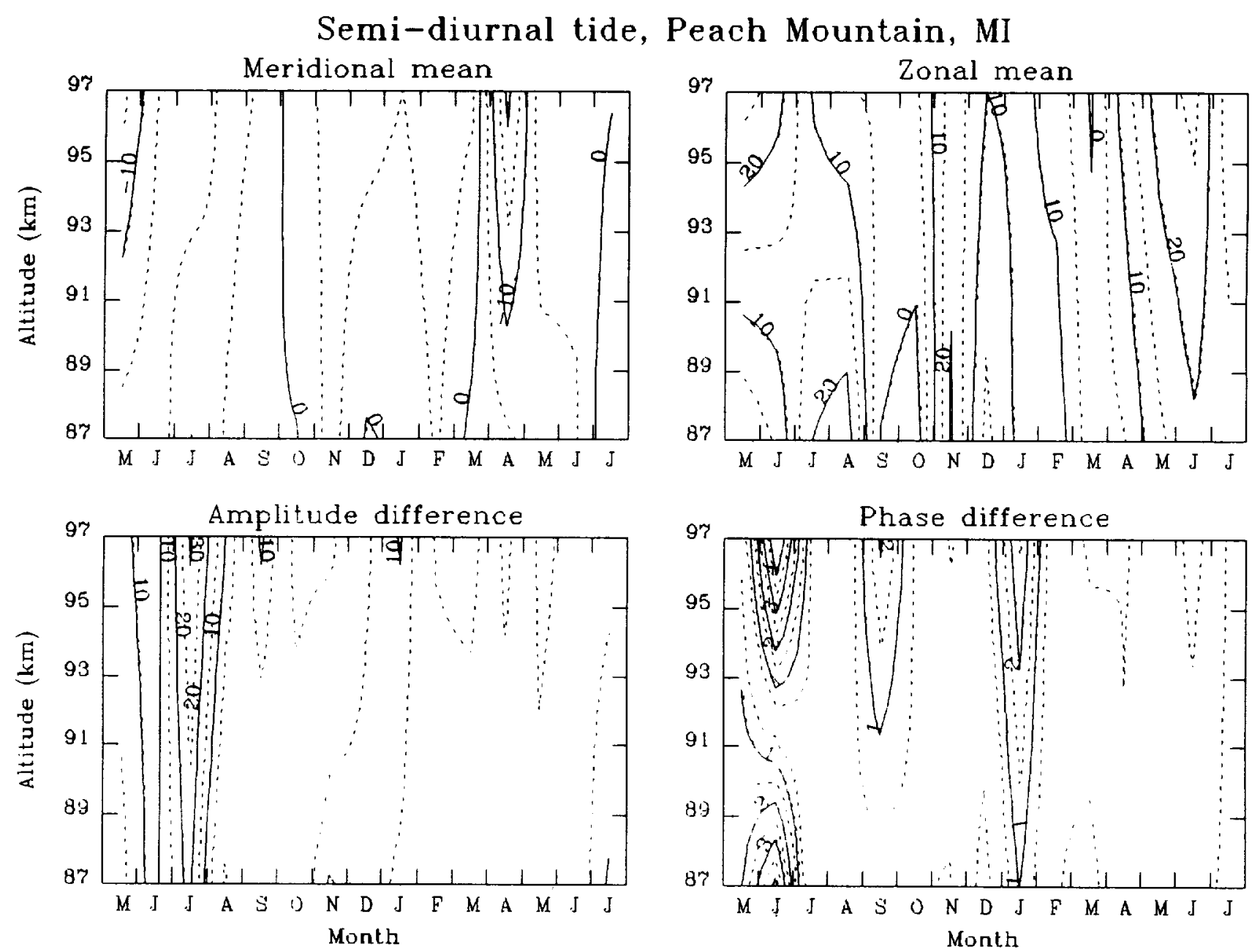

Figure 6. (Top) Amplitude of the mean horizontal components with north and east positive. The solid contours are shown every $10 \mathrm{~m} / \mathrm{s}$. (Bottom) Difference values between the zonal and meridional semidiurnal amplitude and phase. The first contours correspond to $5 \mathrm{~m} / \mathrm{s}$ and 0.5 hour for the amplitude and phase differences, respectively. A 3-hour difference between meridional and zonal phase is implicitly assumed in the presentation.

numerous in situ photometric measurements accomplished by sounding rockets have provided consistently similar altitudinal profiles of volume emission rate for both the hydroxyl and

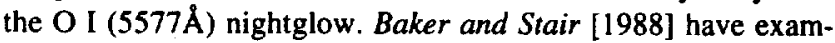
ined several decades of rocket-borne photometric determinations of peak hydroxyl emission and have found that the mean altitude of emission is $87 \mathrm{~km}$ with a full width at half maximum (FWHM) of $6 \mathrm{~km}$. There are differences between individual profiles which may be caused by higher frequency gravity wave transits through the emission regions, but the general features describing peak emission altitude and width of the emission region are repeatable. Similarly, Nardi [1991] surveyed the series of altitudinal profiles of sounding rocket O I (5577 $\AA$ ) measurements and concluded that the mean emission height was $97 \mathrm{~km}$, with a FWHM of $9 \mathrm{~km}$.

There are several unique concerns relating to o I $(5577 \AA)$ measurements that may contaminate the assessment of lower thermospheric winds: (1) upper thermospheric O I (5577 $\AA$ ) contributions and (2) auroral contamination. The O I (5577 $\AA$ ) nightglow is composed of two distinct, separate layers: the lower layer that is of interest to this current study and an upper layer centered near $240 \mathrm{~km}$ with a FWHM of $50 \mathrm{~km}$. Typical peak altitude volume emission rates for the layers are 50-360 photons $/ \mathrm{s}-\mathrm{cm}^{3}$ for the lower and 3-4 photons $/ \mathrm{s}-\mathrm{cm}^{3}$ for the upper (see, e.g., Wiens et al. [1988] for an altitudinal profile). The contribution from the higher altitude to the line of sight columnar measurement originates from a dissociative recombination reaction involving the molecular oxygen ion and would preferentially contaminate twilight observations. However, the several minute frequency of data acquisition and the short duration of $F$ region illumination during the nightglow observations acts to mitigate the seriousness of the upper thermosphere contribution. In a more detailed study, Wiens et al. [1988] conclude that wind vectors for the lower thermosphere are correct to $\pm 20 \%$ of their actual values when account is taken of the upper thermospheric component. Similarly, Won [1994] simulated upper thermospheric O I (5577 $)$ contributions to ground-based wind measurements and determined comparable values.

Auroral contamination to observed O I (5577 $\AA$ ) measurements could be extremely serious [Cogger et al., 1985; Wiens et al., 1988]. Dependent upon the mean energy of the precipitating particles, the altitude of peak auroral O I ( $5577 \AA)$ emission ranges from less than $100 \mathrm{~km}$ to as high as $400 \mathrm{~km}$. The 

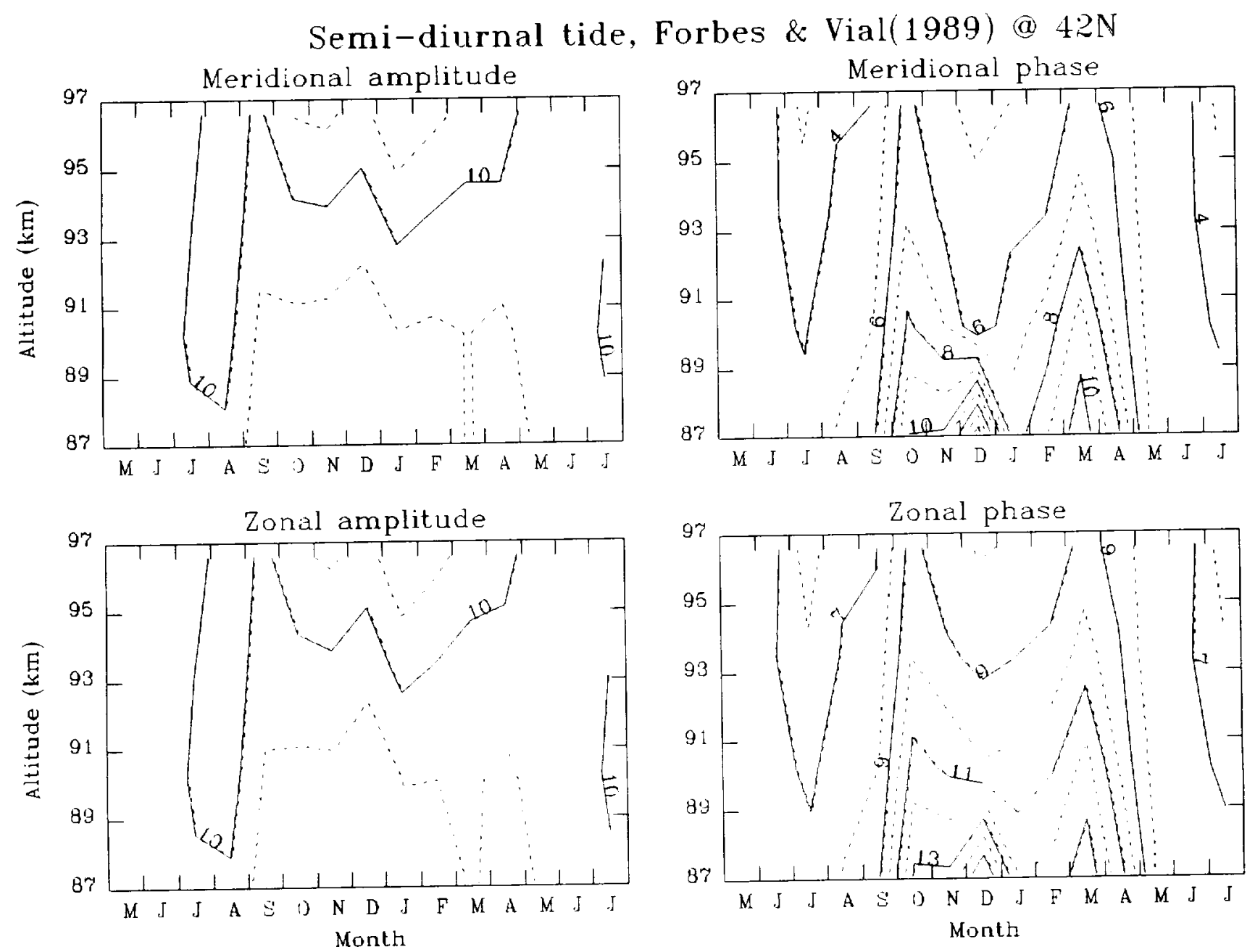

Figure 7. Model output from the Forbes and Vial [1989] simulation of the solar semidiurnal tide for $42^{\circ} \mathrm{N}$ latitude. The solid contours are shown every $10 \mathrm{~m} / \mathrm{s}$ for amplitude and every 2 hours for the phase. The close similarity between meridional and zonal components is inherent to the model.

radiative lifetime of the emitting $O\left({ }^{1} S\right)$ state is less than $1 \mathrm{~s}$ implying that the retrieved temperature could be used as a measure of auroral contamination: a high and variable neutral temperature combined with a high and variable intensity would indicate potential auroral contamination. The airglow observatory is located at a high midlatitude site geomagnetically and is susceptible to auroral displays. During the period of interest, several auroral events were observed: September 13, 1993, with $A_{p}=91$; February 21, 1994, with $A_{p}=93$; April 3, 1994, with $A_{p}=92$; and April 17, 1994, with $A_{p}=100$. In each of these cases, both the neutral temperature determination and the emission rate of O I $(5577 \AA)$ indicated that the Fabry-Pérot interferometer was observing aurora, and consequently, their wind data were disregarded from this study.

Several attempts have been made to check the consistency of the wind measurements from the hydroxyl and O I $(5577 \AA)$ nightglow above Peach Mountain with those obtained independently. In a paper by Burrage et al. [1995], high resolution Doppler interferometer (HRDI) limb measurements of the molecular oxygen nightglow have been compared on a one-toone basis with both radar and optical observations, including some of the measurements utilized in this present study. Approximately 90 coincident samplings were found for the period
June 1993 to September 1994 with very good agreement in the meridional wind values. Gault et al. (Validation of $O\left({ }^{1} \mathrm{~S}\right)$ wind measurements by WINDII: The wind imaging interferometer on UARS, submitted to Journal of Geophysical Research, 1995) perform a similar validation employing WINDII O I $(5577 \AA)$ measurements and Peach Mountain data for 15 nights from June 1993 to January 1994. In this case the Peach Mountain wind was converted to the WINDIl line of sight direction prior to comparison. The results indicate that the mean wind difference was 4.0 and $-5.8 \mathrm{~m} / \mathrm{s}$ for the two different fields of view of WINDII, which is reasonably good for the range of wind values and the difficulties in assuring both temporal and spatial common volume coordinations. In the HRDl measurements, the altitudinal resolution was $5 \mathrm{~km}$, with the nightglow values corresponding to a height of $95 \mathrm{~km}$. For WINDII, height resolution was a little greater than $2 \mathrm{~km}$, with maximum nightglow emission at or above $95 \mathrm{~km}$.

Finally, Niciejewski and Killeen [1995] describe a method to infer the altitude of the hydroxyl airglow from temperature measurements acquired by a collocated Michelson interferometer. This experiment observes the rotational development of hydroxyl emission in the Meinel band system and determines neutral temperature of the emission layer by assuming a 
Boltzmann population distribution. A long-term measurement campaign initiated in December 1992 provided a time series from which the annual and semiannual variations in temperature could be extracted. The results of the phases for these variations are consistent with an emission layer in the mesosphere in the vicinity of $87 \mathrm{~km}$.

In summary, after the removal of data points contaminated by emission from auroral precipitation, the altitudes corresponding to the hydroxyl and O I (5577 $)$ semidiurnal fits were assumed to correspond to the generally accepted values in the mesosphere and the lower thermosphere. There is the possibility that higher frequency gravity wave components could produce vertical shifts in the emission layer, but for this study a fixed altitude for the emissions is assumed. In addition, it is assumed that the volume emission rate altitude profiles are Gaussian, and consequently, the measured winds are heavily weighted to the altitudes representing peak emission rate.

\section{Comparison With Radar Determinations}

There are several radar sites which perform observations near the latitude of the Peach Mountain airglow observatory. Manson et al. [1989] summarize the tidal climatology from the network of medium frequency (MF), meteor, and low frequency (LF) radars operational at that epoch. The set of radar sites includes Saskatoon $\left(52^{\circ} \mathrm{N}\right)$, Garchy $\left(47^{\circ} \mathrm{N}\right)$, Monpazier $\left(44^{\circ} \mathrm{N}\right)$, Collm $\left(52^{\circ} \mathrm{N}\right)$, Durham $\left(43^{\circ} \mathrm{N}\right)$, and Christchurch $\left(44^{\circ} \mathrm{S}\right)$. The features of the semidiurnal tide that are evident from the 30-day averaged contour plots are (1) when both meridional and zonal data are available, the amplitude difference between them is less than or equal to $10 \mathrm{~m} / \mathrm{s}$; (2) the amplitudes are greater at 97 $\mathrm{km}$ than at $87 \mathrm{~km}$; (3) at $97 \mathrm{~km}$, the amplitude is maximum during the autumnal equinox and the winter solstice for Saskatoon, Garchy, Monpazier, and Collm, and during both vernal and autumnal equinoxes for Durham; (4) at $87 \mathrm{~km}$, the amplitude is generally greatest during the autumnal equinox; (5) the phases are generally within quadrature for the meridional and the zonal pairs at both 97 and $87 \mathrm{~km}$ altitude, though the phase difference may amount to 2 hours at Saskatoon; (6) the phases undergo rapid transitions during both equinoxes.

The peak amplitude values observed at Peach Mountain are similar to those observed at the radar sites, surpassing $35 \mathrm{~m} / \mathrm{s}$ at $97 \mathrm{~km}$ altitude. The amplitude is greater at the higher altitude. However, the winter solstice maximum recorded by the radar sites is not evident at Peach Mountain, where a minimum is measured. The seasonal amplitude behavior at Peach Mountain is more like that observed at Durham, though the magnitudes for the optical measurements are higher. In addition, the seasonal development of the phases are more similar between Durham and Peach Mountain, than for any other site. Durham is the nearest to Peach Mountain of the sites used by Manson et al. [1989] and the similarities between the two may just reflect that fact. Detailed differences between the two data sets could result from interannual variations, since the Durham data were acquired between 1978 and 1984 .

Regarding mean winds, a recent compilation by Manson et al. [1987] includes a re-analysis of Durham meteor data from 1978 to 1984 . The mean winds between 87 and $97 \mathrm{~km}$ at Durham are strikingly similar to the Peach Mountain mean winds: the meridional wind is equatorward during the summer and poleward during the winter; the zonal wind is always eastward, maximizing during the summer months, then decreasing in strength during autumnal equinox, increasing during the winter months, before decreasing once again following the vernal equinox.

\section{Comparison With a Numerical Model}

The method by which the neutral wind data were employed in order to determine semidiurnal parameters differs slightly from that used by other investigators. Though the optical experiment operated on all nights, there were several occasions when cloud cover contaminated determinations for only a part of a night. Consequently, constructing an hourly binned monthly average wind was not a satisfactory process. The statistical significance of each hourly bin of the monthly average differed markedly, primarily because the number of entries per bin was dramatically different. The approach used in this study of using each independent measurement per month to fit the semidiurnal tide was chosen instead. The monthly numerical representation would not necessarily fit any given night of wind data in that month, though most nights sets would come close as shown in Figure 4. The detailed day-to-day variability of the wind measurements is the subject of a future study of this set of data.

The Forbes and Vial [1989] numerical model has become a standard against which semidiurnal tidal data sets are compared. The formulation is valid for the altitude range $80-100$ $\mathrm{km}$. With the addition of a numerical functional description of winds from 100 to $150 \mathrm{~km}$, the original model was extended upward [Forbes et al., 1994]. The model provides monthly simulations of the effect of the semidiurnal tide on mesospheric and lower thermospheric neutral winds. The amplitudes of the semidiurnal tide as simulated by the model are generally less than those observed at Peach Mountain. The general behavior of the phase is similar with the observed phase, though the magnitudes differ by several hours. The rapid phase changes during the autumnal equinox are evident in both the model and the Peach Mountain data. However, the model phase is symmetric about the winter solstice while the observed phase symmetry is not as well defined. The numerical model, by its very construction, provides nearly identical meridional and zonal amplitudes and phases which are in quadrature. Attempts at discerning differences between the meridional and zonal semidiurnal characteristics of the Peach Mountain data sets indicate that for much of the 15-month campaign effort, the wind data may be well described as semidiurnal.

The observed semidiurnal tidal data show an interannual variation between the two summer months that were included in the campaign. The 1994 summer period is more typical of the rest of the data in that there is little difference between the meridional and zonal semidiurnal tidal amplitudes, and the phases are nearly in quadrature with each other. The 1993 summer period is anomalous and difficult to describe from the standpoint of tidal dynamics. During the summer of 1993, an all-sky imager monitoring hydroxyl nightglow was operational and collocated at Peach Mountain. $W u$ and Killeen [1994] discuss the frequency of occurrence of bright, wavy airglow structure observed during the summer months. The allsky imager operated on all clear nights. The occurrence frequency for visible and significant gravity wave airglow signatures was $70 \%$ during the early summer months, dropping to near zero in August and thereafter. It is possible, then, that there was significant interference between the semidiurnal tide and the gravity waves resulting in a masking of the tidal signatures in the neutral wind data. Note that once the recurrent 
waves disappeared, the semidiurnal tidal wind signatures became much clearer.

\section{Conclusions}

The study just completed has shown the potential of the optical technique for simultaneously observing both mesospheric and lower thermospheric dynamics from a groundbased airglow observatory. The advent of the scientific grade, low-noise bare CCD has provided a unique tool for observing the line profile of a bright, near-infrared hydroxyl emission. Compromises in the remainder of the design of the Fabry-Perot interferometer experiment allowed reasonable observations of both a green and the near-infrared emission. The technique promises to provide even more additional altitudinal discrimination by including both sodium and molecular oxygen monitoring capabilities. This would provide diagnostic measurements independent of the radar network and would provide observations during nocturnal periods when MF radar echoes are much weaker or too noisy. However, true unattended observations using the current experimental design will require the replacement of the cryogen requirement.

The 15-month study has shown the major influence of the semidiurnal tide on neutral wind observations in the mesosphere and lower thermosphere. Except for the summer 1993 period, the orthogonal wind measurements may be easily associated with the semidiumal tide. The observed meridional and zonal semidiurnal amplitudes are nearly identical and the phases are usually in quadrature with one another. The measured tidal amplitude is greater at the higher altitude, though the seasonal behavior at both altitudes is similar with greater amplitudes during August/September and April/May. The mean winds show annual variation in the meridional flow, being equatorward from May to October and poleward during the winter. The zonal flow is primarily eastward during the entire observational window with higher speed flows during May/June at the higher altitude and June/July at the lower altitude. The observations, in context with collocated all-sky imagery and more detailed temperature measurements, may provide a mechanism by which contributions from gravity waves and other tidal frequencies may be estimated.

The comparison with the numerical model has shown that these observations also tend to indicate greater amplitudes for the semidiurnal tide by a factor of 2 times or greater. This may be caused by the differing definitions of "monthly mean" as well as interannual variability. The similarities between the optical data and the Durham meteor radar data are encouraging, even though data were acquired in different years. Rapid phase variations during the equinox are common to both measurements and model, though model output indicates much more symmetry between the two equinoxes. Continued improvements in the numerical model based on data acquired by both radar and optical techniques may eventually provide an operational description for the lower boundary that could be used in the TGCM style models.

Acknowledgments. The author is deeply appreciative for the gracious long-term support from NSF through grants ATM-9002607 and ATM-9301867. Support from NASA grant NAG1-1315 was also used to sponsor this long-term effort. All equipment was provided by Space Physics Research Laboratory and University of Michigan funding. Much of the initial design, construction, and deployment was performed by Gerry McCormac. Many students received training over the years from this experiment and their contributions are much appreciated: Doug Drob, Gerard Roe, Steve Carr, Matt Turnbull, Lisa Gillikin, and Youngin
Won. Discussions with Ganduri Murty, Alan Burns, Roberta Johnson, and Qian $W u$ are also appreciated. Access to the numerical model was possible with the helpful assistance of Youngin Won, and through him, Jeff Forbes.

\section{References}

Baker, D. J., and A. T. Stair Jr., Rocket measurements of the altitude distributions of the hydroxyl airglow, Phys. Scr., 37, 611, 1988.

Burrage, M. D., et al., Validation of mesosphere and lower thermosphere winds from the high resolution Doppler imager on UARS, $J$. Geophys. Res., in press, 1995.

Chapman, S., and R. S. Lindzen, Atmospheric Tides, D. Reidel. Norwell, Mass., 1970

Clark, R. R., Upper atmosphere observations of waves and tides with the UNH meteor radar system at Durham $43^{\circ} \mathrm{N}(1977,1978$, and 1979), J. Atmos. Terr. Phys., 45, 621, 1983.

Cogger, L. L., J. S. Murphree, C. A. Tepley, and J. W. Meriwether Jr., Measurements of the $E$ region neutral wind field, Planet. Space Sci., 33, 373, 1985.

Forbes, J. M. and F. Vial, Monthly simulations of the solar semidiurnal tide in the mesosphere and lower thermosphere, J. Atmos. Terr. Phys., 51, 649, 1989.

Forbes, J. M., et al., Semidiurnal tide in the $80-150 \mathrm{~km}$ region: An assimilative data analysis. J. Atmos. Terr. Phys., 56, 1237, 1994.

Gardner, C. S., D. C. Senft, T. J. Beatty, R. E. Bills, and C. A. Hostetler, Rayleigh and sodium LIDAR techniques for measuring middle atmosphere density, temperature and wind perturbations and their spectra. in WITS Handbook, vol. 2, edited by C. H. Liu, p. 148, Univ. of Illi. Urbana, 1989.

Hernandez, G., and J. L. Smith, Mesospheric wind determinations and the $\mathrm{P}_{1}(2)_{\mathrm{cdd}}$ lines of the $\mathrm{X}^{2} \Pi \mathrm{OH}(8-3)$ band, Geophys. Res. Lett., 11 . 534,1984

Hernandez, G., G. J. Fraser, and R. W. Smith, Mesospheric 12-hour oscillation near South Pole. Antarctica, Geophys. Res. Lett., 20, 1787 , 1993.

Hines, C. O., G. W. Adams, J. W. Brosnahan, F. T. Djuth, M. P. Sulzer, C. A. Tepley, and J. S. van Baelen, Multi-instrument observations of mesospheric motions over Arecibo: Comparisons and interpretations. J. Atmos. Terr. Phys., 55, 241, 1993.

Killeen, T. L., and P. B. Hays, Doppler line profile analysis for a multichannel Fabry Perot interferometer, Appl. Opt., 23, 612, 1984.

Lloyd, N., A. H. Manson, D. J. McEwen, and C. E. Meek, A comparison of middle atmospheric dynamics at Saskatoon $\left(52^{\circ} \mathrm{N}, 107^{\circ} \mathrm{W}\right)$ as measured by medium-frequency radar and a Fabry-Perot interferometer, J. Geophys. Res., 95, 7653, 1990.

Manson, A. H., and C. E. Meek, Winds and tidal oscillations in the upper middle atmosphere at Saskatoon $\left(52^{\circ} \mathrm{N}, 107^{\circ} \mathrm{W}, L=4.3\right)$ during the year June 1982 - May 1983, Planet. Space Sci., 32, 1087, 1984.

Manson, A. H., et al., Mean winds of the upper middle atmosphere $(-70-$ $110 \mathrm{~km}$ ) from the global radar network: Comparisons with CIRA 72 , and new rocket and satellite data, Adv. Space Res., 7(10), 143, 1987.

Manson, A. H., C. E. Meek, H. Teitelbaum, F. Vial, R. Schminder, D. Kürschner, M. J. Smith, G. J. Fraser, and R. R. Clark, Climatologies of semi-diurnal and diurnal tides in the middle atmosphere (70-110 $\mathrm{km}$ ) at middle latitudes $\left(40-55^{\circ}\right), \mathrm{J}$. Atmos. Terr. Phys., 51, 579, 1989.

Meriwether, J. W.. Jr., and P. Shih, On the nighttime signatures of thermospheric winds observed at Sondrestrom, Greenland, as correlated with interplanetary magnetic field parameters, Ann. Geophys., 5A, 329,1987

Meriwether, J. W., Jr., C. A. Tepley, S. A. Price, P. B. Hays, and L. L. Cogger, Remote ground-based observations of terrestrial airglow emissions and thermospheric dynamics at Calgary, Alberta, Canada, Opt. Eng., 22, 128, 1983.

Meriwether, J. W., Jr., T. L. Killeen, F. G. McCormac, A. G. Burns, and R. G. Roble, Thermospheric winds in the geomagnetic polar cap for solar minimum conditions, J. Geophys. Res., 93, 7478, 1988.

Mulligan, F. J., A new technique for the real-time recovery of Fabry Perot line profiles, J. Phys. E Sci. Instrum., 19, 545, 1986.

Nardi, B., An inversion technique to recover lower thermospheric winds from space-borne remote measurements of [Ol] $5577 \AA, \mathrm{Ph}$. D. thesis, Univ. of Mich., Ann Arbor, 1991.

Niciejewski, R. J. and T. L. Killeen, Annual and semi-annual oscillations in the upper mesosphere, Geophys. Res. Lett., in press, 1995.

Niciejewski, R., T. L. Killeen, and M. Tumbull, Ground-based FabryPérot interferometry of the terrestrial nightglow with a bare charge- 
coupled device: Remote field site deployment, Opt. Eng., 33, 457, 1994.

Rees, D., A. Aruliah, T. J. Fuller-Rowell, V. B. Wickwar, and R. J. Sica, Winds in the upper mesosphere at mid-latitude: First results using an imaging Fabry-Perot interferometer, Geophys. Res. Lett., 17, 1259, 1990.

Roble, R. G., E. C. Ridley, A. D. Richmond, and R. E. Dickinson, A coupled thermosphere/ionosphere general circulation model, Geophys. Res. Lett., 15, 1325, 1988.

Sivjee, G. G., R. L. Walterscheid, J. H. Hecht, R. M. Hamwey, G. Schubert, and $A$. B. Christensen, Effects of atmospheric disturbances on polar mesopause airglow OH emissions, J. Geophys. Res., 92, 7651, 1987.

Wand, R. H., Seasonal variations of lower thermospheric winds from the Millstone Hill incoherent scatter radar, J. Geophys. Res., 88, 9227, 1983.
Wiens, R. H., G. G. Shepherd, W. A. Gault, and P. R. Kosteniuk, Optical measurements of winds in the lower thermosphere, J. Geophys. Res., $93,5973,1988$.

Won, Y., Studies of thermospheric neutral winds utilizing ground-based optical and radar measurements, Ph. D. thesis, Univ. of Mich., Ann Arbor, 1994.

Wu, Q., and T. L. Killeen, Seasonal dependence of mesospheric gravity wave activity observed in hydroxyl airglow images at mid-latitudes (abstract), Eos, Trans. AGU, 75(44), Fall Meet. Suppl., 495, 1994.

T. L. Killeen and R. J. Niciejewski, Space Physics Research Laboratory, University of Michigan, 2455 Hayward Street, Ann Arbor, MI 48109-2143.

(Received January 27, 1995; revised August 25, 1995; accepted August 27, 1995.) 